\title{
Article \\ Surface Characterization and Performance Evaluation of Nitrogen Implanted Coinage Dies
}

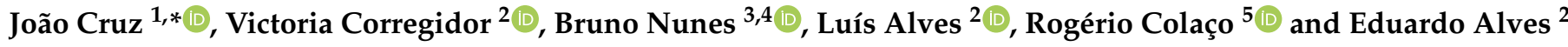 \\ 1 Laboratório de Instrumentação, Engenharia Biomédica e Física da Radiação (LIBPhys-UNL), \\ Departamento de Física, Faculdade de Ciências e Tecnologia da Universidade Nova de Lisboa, \\ Monte da Caparica, 2892-516 Caparica, Portugal \\ 2 Centro de Ciências e Tecnologias Nucleares (C2TN), Instituto Superior Técnico, Universidade de Lisboa, \\ E.N. 10 km 139,7, 2695-066 Bobadela LRS, Portugal; vicky.corregidor@ctn.tecnico.ulisboa.pt (V.C.); \\ lcalves@ctn.tecnico.ulisboa.pt (L.A.); ealves@ctn.tecnico.ulisboa.pt (E.A.) \\ 3 Centro de Química Estrutural (CQE), Instituto Superior Técnico, Universidade de Lisboa, \\ Av. Rovisco Pais 1, 1049-001 Lisboa, Portugal; bruno.nunes@ist.utl.pt \\ 4 Atlântica, Instituto Universitário, Fabrica da Pólvora, 2730-036 Barcarena, Portugal \\ 5 Instituto de Engenharia Mecânica (IDMEC), Instituto Superior Técnico, Universidade de Lisboa, \\ Av. Rovisco Pais 1, 1049-001 Lisboa, Portugal; rogerio.colaco@tecnico.ulisboa.pt \\ * Correspondence: jdc@fct.unl.pt; Tel.: +351-212948576
}

check for updates

Citation: Cruz, J.; Corregidor, V.; Nunes, B.; Alves, L.; Colaço, R.; Alves, E. Surface Characterization and Performance Evaluation of Nitrogen Implanted Coinage Dies. Processes 2022, 10, 479. https:// doi.org/10.3390/pr10030479

Academic Editors: Krzysztof Talaśka, Szymon Wojciechowski and Antoine Ferreira

Received: 28 January 2022

Accepted: 25 February 2022

Published: 27 February 2022

Publisher's Note: MDPI stays neutral with regard to jurisdictional claims in published maps and institutional affiliations.

Copyright: (C) 2022 by the authors. Licensee MDPI, Basel, Switzerland. This article is an open access article distributed under the terms and conditions of the Creative Commons Attribution (CC BY) license (https:// creativecommons.org/licenses/by/ $4.0 /)$.

\begin{abstract}
Very high fluence implantation of ${ }^{14} \mathrm{~N}^{+}$ions was used to promote the formation of a nitride layer on the surface of steel coinage dies used by the Portuguese Mint. Die steel samples were studied before and after implantation at $90 \mathrm{keV}$ plus $30 \mathrm{keV}$ for two nominal fluences, $5.0 \times 10^{17} \mathrm{at} / \mathrm{cm}^{2}$ and $1.0 \times 10^{18}$ at $/ \mathrm{cm}^{2}$, and for two implantation temperatures, room and liquid nitrogen temperature. Surface characterization was carried out by ultramicrohardness indentation, Atomic Force Microscopy (AFM), and Rutherford Backscattering Spectrometry (RBS). A significant increase (factor two) in depth reached by the implanted nitrogen was observed for LN2 implantations, which, to our knowledge, was never reported before. Results point out the benefit of nitrogen implantation at room temperature with a nominal fluence of $5.0 \times 10^{17}$ at $/ \mathrm{cm}^{2}$, which raised the hardness of the dies by $\sim 40 \%$ (from $6.2 \pm 0.5$ to $8.7 \pm 0.7 \mathrm{GPa}$ ). Nitrogen implanted dies were used to mint circulating two cents euro coins and their performance was assessed, showing that when compared to Vautrol coated dies (standard coating used by the Portuguese Mint), the crack density was lower and similar wear resistance was observed.
\end{abstract}

Keywords: nitrogen; ion implantation; depth profiling; coinage dies; surface analysis; hardness

\section{Introduction}

In Portugal, coin emission has always been a State privilege and the Portuguese Mint (INCM, Imprensa Nacional-Casa da Moeda) is the only entity that mints metallic coins, in quantities that are legally defined by governmental decrees. Metallic currency needs are around 100 million euro circulating coins with normal finish, every year. To accomplish this coin production rate, the Portuguese Mint uses coining dies made of special cold work tool steels from Böhler [1] coated either with a few-micrometer electrodeposited hard chromium layer or with a non-stick coating (Vautrol) from VTT [2].

This last type of die coating is being used by INCM for the two euro cents coin, which is made of copper-covered steel and is $18.75 \mathrm{~mm}$ in diameter. The coining presses that are used to mint this coin reach a production rate as high as 800 coins per minute. The wear of the die after several thousands of punching operations leads to the appearance of small cracks and to severe alterations in the reliefs, and thus dies must be replaced after $\approx 100,000$ strikes. As such, INCM is looking for a new process of increasing die lifetime that complies with environmental best practices. 
High fluence ion implantation of nitrogen ions is a well known and effective solution for enhancing the lifetime and improving the performance of many types of tools for which wear, friction, fatigue and corrosion problems are present [3-15]. For instance, Iwaki [3] implanted ${ }^{14} \mathrm{~N}^{+}$ions (implantation energy $=75 \mathrm{keV}$, nominal fluences $=3.0 \times 10^{17}, 5.0 \times 10^{17}$ and $1.0 \times 10^{18} \mathrm{at} / \mathrm{cm}^{2}$ ) on AISI H13 and AISI H13 prehardened steel samples. As the fluence increased, the relative hardness rose gradually and at higher fluences it saturated with improvements of $\approx 50 \%$ for the prehardened $\mathrm{H} 13$ steel and $\approx 35 \%$ for the H13 steel. After the nitrogen implantations, the friction coefficient decreased and the wear resistance improved. Wang et al. [4] implanted 9Cr18 steel samples at room temperature (RT) with ${ }^{14} \mathrm{~N}^{+}$ions (implantation energy $=100 \mathrm{keV}$, nominal fluence $=3.0 \times 10^{17} \mathrm{at} / \mathrm{cm}^{2}$ ), which led to enhanced abrasion wear properties and improved chemical corrosion resistance after nitrogen implantation. Dryzek et al. [5] observed that austenitic stainless steel (X10CrNiTi189) after ${ }^{14} \mathrm{~N}^{+}$implantations (implantation energy $=100 \mathrm{keV}$, nominal fluences $=3.0 \times 10^{17}$ and $8.0 \times 10^{17}$ at $\left./ \mathrm{cm}^{2}\right)$ followed by annealing $\left(T<320{ }^{\circ} \mathrm{C}\right)$ presented beneficial effects on microhardness and wear resistance, but no reduction of the friction coefficient was observed. In turn, Bredell and Malherbe [6] studied tool steel samples implanted with $100 \mathrm{keV}^{14} \mathrm{~N}^{+}$ions at liquid nitrogen (LN2) temperature to nominal fluences of $3.0 \times 10^{17}$ and $1.0 \times 10^{18} \mathrm{at} / \mathrm{cm}^{2}$. The thickness of the implanted layer was determined from several depth profiles obtained using Auger electron spectroscopy (AES) combined with argon sputtering. It showed that implanted nitrogen presented an almost gaussian profile with the projected range $\left(R_{p}=110 \mathrm{~nm}\right)$ and straggling $\left(\Delta R_{p}=57 \mathrm{~nm}\right)$ values in good agreement with LSS theory [16]. An oxide layer with $\approx 80 \mathrm{~nm}$ was also detected and, according to the authors [6], it was caused by enhanced diffusion of oxygen into the radiation-induced damaged steel layer. Being thinner than the nitride layer, this oxidized layer should not significantly affect the hardness results [6]. Two very recent papers also address nitrogen implantation in steel. Piotrowska et al. [14] studied RT ${ }^{14} \mathrm{~N}^{+}$ion implantation (implantation energy $=35 \mathrm{keV}$, nominal fluence $=5.0 \times 10^{17} \mathrm{at} / \mathrm{cm}^{2}$ ) on 3162 steel alloy. The authors observed a $45 \%$ increase in hardness after nitrogen implantation and a $17 \%$ drop in the friction coefficient. Xie et al. [15] observed that after ${ }^{14} \mathrm{~N}^{+}$implantations (implantation energies $=60,80$ and $100 \mathrm{keV}$, nominal fluence $=2.0 \times 10^{17} \mathrm{at} / \mathrm{cm}^{2}$ ) the hardness of AISI M50 steel increased by $\approx 30 \%$ (100 keV implantation energy) and the friction coefficient droped by $\approx 7 \%$ (same implantation energy). X-ray Photoelectron Spectroscopy (XPS) and Raman spectroscopy results pointed to the formation of $\mathrm{Fe}_{x} \mathrm{~N}$ and $\mathrm{Cr}_{2} \mathrm{~N}$ and $\alpha-\mathrm{Fe}_{2} \mathrm{O}_{3}$ and $\mathrm{Fe}_{3} \mathrm{O}_{4}$, respectively. In summary, nitrogen implantation improves wear resistance, decreases the friction coefficient and increases hardness.

This hardness increase may be explained by two factors [6]: (i) nitride and/or carbonitride formation combined with substitutional and interstitial nitrogen, and (ii) radiation damage. As for this last factor, implantation damage can extend far beyond the projected range, $R_{p}$, of the implanted ions, increasing the hardness [6]. Additionally, cooling during implantation may cause an additional hardening, owing to a martensitic phase transformation, precipitating mainly on grain boundaries [6].

Optimum energy, fluence, angle of incidence and the temperature of implantation are dependent on the metallic alloy of the blank, on the reliefs and on the steel of the dies. In this work, the feasibility of applying nitrogen implantation to improve the service life of dies used by the INCM to mint the circulating two cents euro coin has been investigated.

The work was conducted in two phases. In the first phase, ${ }^{14} \mathrm{~N}^{+}$implantations were conducted on INCM coinage die steel samples and analyzed in terms of nitrogen depth distribution, hardness and surface morphological modifications. Rutherford Backscattering Spectrometry (RBS) was used to follow the C, O, Fe and implanted ${ }^{14} \mathrm{~N}$ depth distribution profiles, which allowed us to measure the influence implantation temperature and fluence had on the retained nitrogen. Ultramicrohardness measurements were used to determine hardness variation with implantations. These measurements were used to choose the nominal fluence and temperature conditions for dies implantation. Surface morphology, 
including the formation of saturate solutions and phase transformations, were assessed by Atomic Force Microscopy (AFM).

The second phase was concerned with the evaluation and performance assessment of implanted dies to produce the two cent euro coins at the coining presses at INCM, allowing us to compare implanted dies with Vautrol coated dies in terms of service life, wear (qualitative analysis), and crack density.

\section{Materials and Methods}

Böhler steel K605 [1] samples (see Table 1 for composition), each $3 \mathrm{~mm}$ thick, were mechanically polished using silicon carbide (down to 2400 grid) and diamond past (down to $3 \mu \mathrm{m})$.

Table 1. Composition (average \%) of K605 Böhler steel.

\begin{tabular}{ccccccc}
\hline $\mathbf{C}$ & $\mathbf{S i}$ & $\mathbf{M n}$ & $\mathbf{C r}$ & $\mathbf{M o}$ & $\mathbf{N i}$ & $\mathbf{F e}$ \\
\hline 0.55 & 0.30 & 0.40 & 1.00 & 0.25 & 3.00 & balance \\
\hline
\end{tabular}

The Monte Carlo code SRIM2013 [17] was used to simulate the transport of ${ }^{14} \mathrm{~N}$ in steel. The simulation outputs included the ${ }^{14} \mathrm{~N}$ projected range $\left(R_{p}\right)$ and corresponding straggling $\left(\Delta R_{p}\right)$, the sputtering yield $(S)$, and the fraction of backscattered ${ }^{14} \mathrm{~N}$ ions $(B S)$. These values were used to calculate the implanted profile according to the implanted versus sputtered balance equation [18]:

$$
n(x)=\frac{n_{a}(1-B S)}{2 S}\left[\operatorname{erf}\left(\frac{x-R_{p}+D_{N}\left(S / n_{a}\right)}{\sqrt{2} \Delta R_{p}}\right)-\operatorname{erf}\left(\frac{x-R_{p}}{\sqrt{2} \Delta R_{p}}\right)\right],
$$

where $x$ stands for depth, $n_{a}$ is the substrate atomic density, and $D_{N}$ is the nominal fluence. From this equation, the number of ions remaining in the substrate $D_{I}$ (retained fluence) is given simply as:

$$
D_{I}=\int_{0}^{\infty} n(x) d x
$$

According to these equations and in order to obtain a saturated profile without going beyond a nominal fluence of $10^{18}$ at $/ \mathrm{cm}^{2}$ (to avoid severe radiation damage effects on the steel and to limit implantations duration), implantations were performed using a combination of two energies, 90 and $30 \mathrm{keV}$, for two nominal fluences, $5.0 \times 10^{17} \mathrm{at} / \mathrm{cm}^{2}$ $\left(3.0 \times 10^{17} \mathrm{at} / \mathrm{cm}^{2}\right.$ at $90 \mathrm{keV}$ plus $2.0 \times 10^{17} \mathrm{at} / \mathrm{cm}^{2}$ at $\left.30 \mathrm{keV}\right)$ and $1.0 \times 10^{18} \mathrm{at} / \mathrm{cm}^{2}$ $\left(6.0 \times 10^{17}\right.$ at $/ \mathrm{cm}^{2}$ at $90 \mathrm{keV}$ plus $4.0 \times 10^{17}$ at $/ \mathrm{cm}^{2}$ at $\left.30 \mathrm{keV}\right)$. These implantations were performed at two different temperatures, namely room temperature (RT) and liquid nitrogen (LN2). All implantations were performed at the Danfysik 1090 high current ion implanter located at the IST Ion Beam Laboratory (Bobadela, Portugal) [19], with a current density of $\approx 20 \mu \mathrm{A} / \mathrm{cm}^{2}$ and a pressure inside the implantation chamber of $\approx 2 \times 10^{-6} \mathrm{mbar}$.

RBS analysis on non-implanted and implanted surfaces was performed using $2.0 \mathrm{MeV}$ ${ }^{4} \mathrm{He}^{+}$beams from the $2.5 \mathrm{MV}$ Van de Graaff accelerator at the same laboratory, with the backscattered ${ }^{4} \mathrm{He}^{+}$ions being detected by two PIN diodes with an energy resolution of $20 \mathrm{keV}$, placed at an angle of $\theta_{\mathrm{lab}}=140^{\circ}$ and $165^{\circ}$ to the beam direction (IBM geometry). Spectra were taken at normal incidence and $45^{\circ}$ target rotation and were simulated using the SIMNRA code [20].

Ultramicrohardness measurements were performed at room temperature in a Shimadzu DUH-211S apparatus with three different normal loads: 5, 10 and $25 \mathrm{mN}$. The loading rates were $0.2926,0.9754$ and $2.2207 \mathrm{mN} / \mathrm{s}$, respectively, with $20 \mathrm{~s}$ at hold time in both maximum and minimum load during unloading.

AFM analysis was carried out in a Veeco CP-II apparatus using a silicon standard tip (Veeco MPP331 with a nominal constant $\mathrm{K}=0.9 \mathrm{~N} / \mathrm{m}$ ) in contact mode. 


\section{Results and Discussion}

\section{1. ${ }^{14} \mathrm{~N}$ Depth Profile}

The RBS spectra simulation was performed using the deficiency method [21,22] to analyze the near surface, as the nitrogen is hardly visible in these spectra. In this method, the spectrum measured before implantation was compared with the spectra measured after the ${ }^{14} \mathrm{~N}$ implantations. The deficiency in the Fe signal caused by the presence of the ${ }^{14} \mathrm{~N}$ and oxygen (the last one, slightly visible in some spectra) was noted and used to obtain the material stoichiometry at the sample surface, as shown in Figure 1.
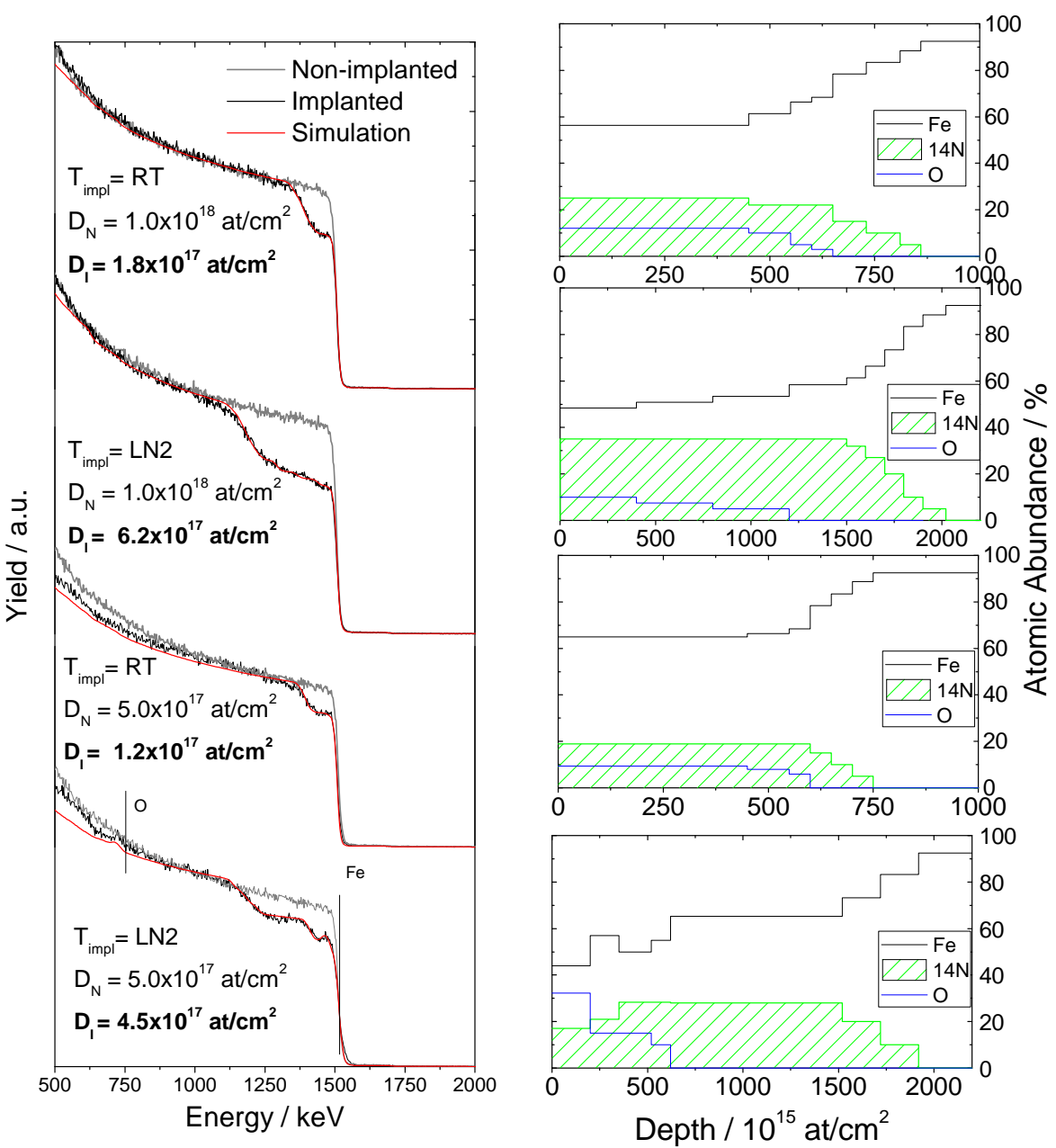

Figure 1. The $2.0 \mathrm{MeV}^{4} \mathrm{He}^{+}$Rutherford backscattering spectra (experimental and simulated) of dies steel samples before and after ${ }^{14} \mathrm{~N}$ implantations, and corresponding depth profiles of ${ }^{14} \mathrm{~N}, \mathrm{O}$ and $\mathrm{Fe}$ extracted from the simulation of the spectra.

In the above figure, it is possible to observe that a saturated ${ }^{14} \mathrm{~N}$ profile is obtained for both nominal fluences and for both implantation temperatures. However, there is a considerable range difference between RT and LN2 cooled implantations. At room temperature, a range of approximately $700 \times 10^{15}$ at $/ \mathrm{cm}^{2}$ was measured for both fluences, in fair agreement with Monte Carlo predictions $\left(860 \times 10^{15} \mathrm{at} / \mathrm{cm}^{2}=100 \mathrm{~nm}\right)$, whereas in cooled implantations the measured range more than doubled, i.e., approximately $1750 \times 10^{15}$ at $/ \mathrm{cm}^{2}$. These results for LN2 cooled implantations are different from the published results by Bredell and Malherbe [6], where a good agreement was shown between the theoretical and experimental $R_{p}$ and $\Delta R_{p}$ values. As far as we know, this temperature effect on the nitrogen implanted depth profile has never been reported before. According to [6], at LN2 temperature there is less nitride formation and solution hardening by free nitrogen dominates. Thus, it may be possible that the excess of nitrogen migrates 
towards the dislocation structures underneath the implanted profile with a concentration that depends on the dislocations density. This dislocation, if it happened, was not detected by Bredell and Malherbe [6], because it was below the detection limits of the AES technique during sputter profiling. Thus, the presence of free nitrogen at LN2 implantations may explain the availability of nitrogen to migrate deeper, but the mechanism proposed in [6] alone does not explain the nitrogen concentrations determined by RBS in our work. Therefore, an alternative mechanism should be proposed.

\subsection{Die Hardness}

Nitrogen implantation effects on the hardness of the dies steel samples are shown in Figures 2 and 3. The first of these figures shows the variation of hardness with nominal fluence for the RT implantations. For all loads, the depth reached goes beyond the implanted layer, meaning that the results may be affected by the bulk hardness of the dies, even considering the radiation damage hardening, which goes deeper in the sample. Nonetheless, the effect of implantation is observable. For the sample with the lowest fluence, it is possible to see an increase of approximately $40 \%$ (from $6.2 \pm 0.5$ to $8.7 \pm 0.7 \mathrm{GPa}$ ) in the hardness as compared with the reference sample (non-implanted die) (values measured with $5 \mathrm{mN}$ loads). For the sample implanted with the highest fluence a decrease of hardness was observed. The hardness increase for the lowest fluence sample is most likely associated with the formation of carbonitrides at the implanted surface $[8,10]$, whereas the decrease for the highest fluence sample may be associated with annealing effects during ion implantation. This high fluence produces severe changes throughout the implanted region with the ${ }^{14} \mathrm{~N}$ reaching a local concentration of 25 at.\% (see Figure 1 ). In fact, Iwaki [3] observed a hardness saturation phenomenon with nitrogen implantation in an H13 alloy tool steel, attributed to the possibly of formation of a brittle phase that reduces the surface hardness. Even though the composition of the studied steel is different, a similar effect may have occurred, since the highest fluence implantation presents almost the same hardness value as the reference.

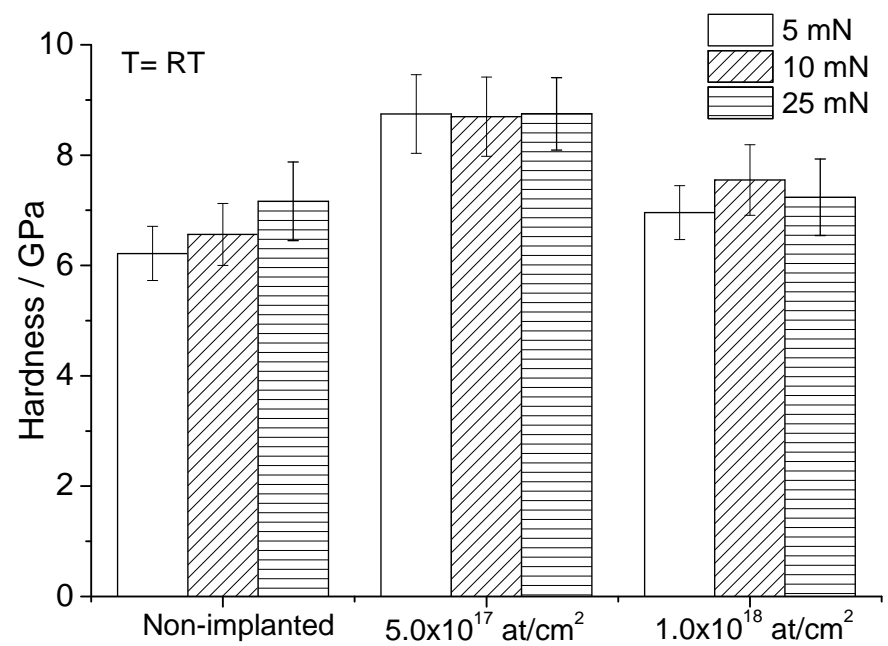

Figure 2. Hardness variation for the dies steel samples, non-implanted and implanted at room temperature, with normal loads of 5, 10 and $25 \mathrm{mN}$.

In Figure 3, corresponding to the dies steel samples implanted at LN2 temperature, it is possible to observe that the reference sample presents a higher hardness value when compared to the reference in Figure 2, after the cooling. This hardness increase is associated with low temperature martensitic transformation of the retained austenite of the dies. After nitrogen implantation, small variations in hardness were observed for the 10 and $25 \mathrm{mN}$ normal loads, while a decrease was observed for $5 \mathrm{mN}$ at the highest fluence. For this temperature, the depths reached both by 5 and $10 \mathrm{mN}$ are still within the implanted layer, while the $25 \mathrm{mN}$ measurements reach the bulk. It is important to mention that for the 
highest fluence implantation, the microstructure of the surface changed, becoming fully rich in precipitates, as can be observed by AFM analysis (Figures 4 and 5). The first of these two figures shows the topographic characterization of the steel samples for both fluences and different temperatures. It shows that after the $5.0 \times 10^{17} \mathrm{at} / \mathrm{cm}^{2}$ nominal fluence implantations, nanometric precipitate-type features appeared in the surface for both temperatures, possibly consisting of some nitrates due the high nitrogen concentration. However, more significant changes in the surfaces were observed upon the implantation at higher fluence, where, for the RT implantation one can observe that no precipitates were formed but a change in the surface roughness seems to have happened, while for the LN2 implantation large precipitates were formed, with dimensions comprised between 0.5 and $1 \mu \mathrm{m}$, fully surrounded by small precipitates. A more detailed description of the large precipitates can be seen in Figure 5. The hardness values taken from such an irregular surface for smaller normal loads may deviate from the real value [9]. Another possibility for the decrease of the $5 \mathrm{mN}$ may be the formation of the same brittle phase as mentioned before. However, in Bredell's paper [6], it was shown that hardening of the surface occurs in Pitho steel implanted with similar conditions. This difference could be related to the depth of analysis. Since for $5 \mathrm{mN}$ the reached depth (110 to $160 \mathrm{~nm})$ is still within the implanted layer, less bulk influence is felt. Nevertheless, a further understanding of the effect of RT and subzero implantation on this steel requires further analysis.

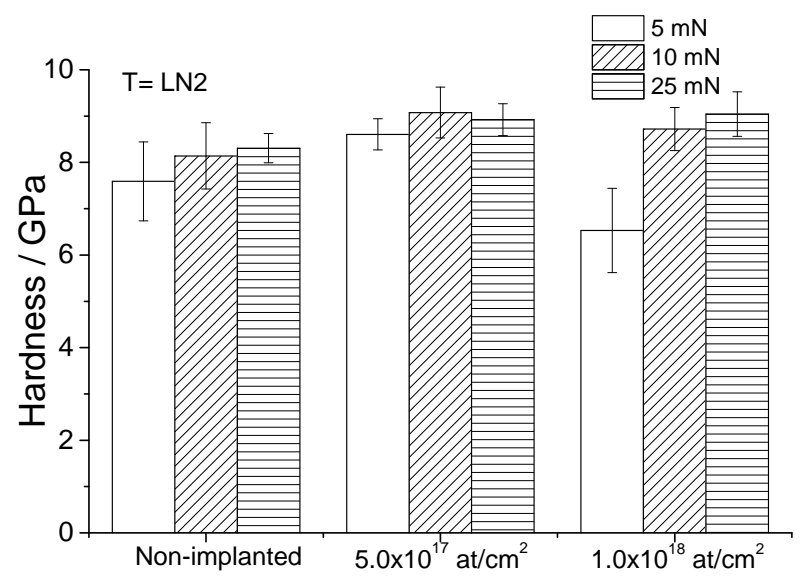

Figure 3. Hardness variation for the dies steel samples, non-implanted and implanted at LN2 temperature, with normal loads of 5, 10 and $25 \mathrm{mN}$.

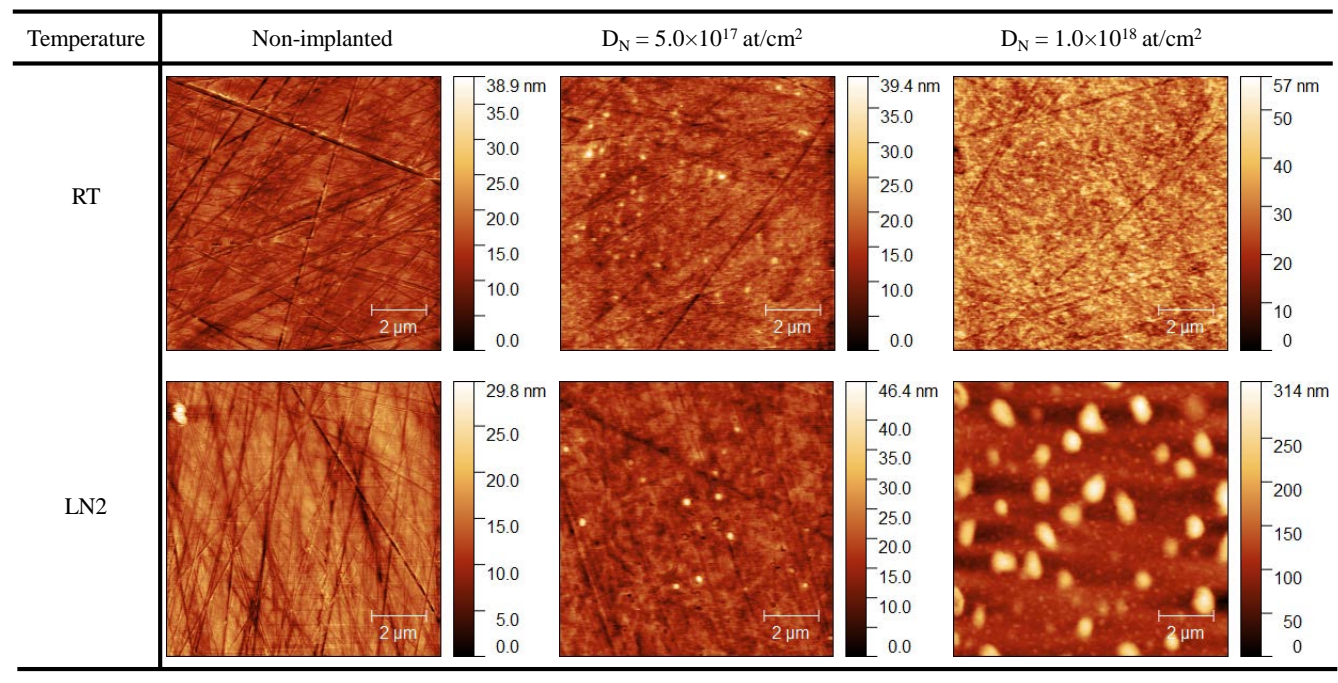

Figure 4. AFM topographic images of the non-implanted and nitrogen implanted die steel samples with nominal fluences of $5.0 \times 10^{17}$ at $/ \mathrm{cm}^{2}$ and $1.0 \times 10^{18} \mathrm{at} / \mathrm{cm}^{2}$ for both room and LN temperatures. 

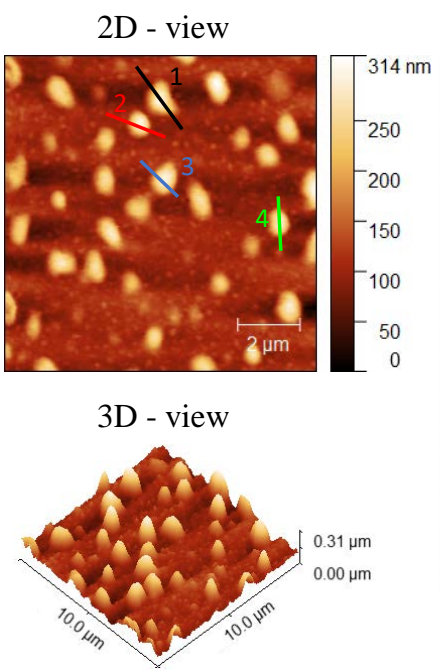

Profiles 1 to 4
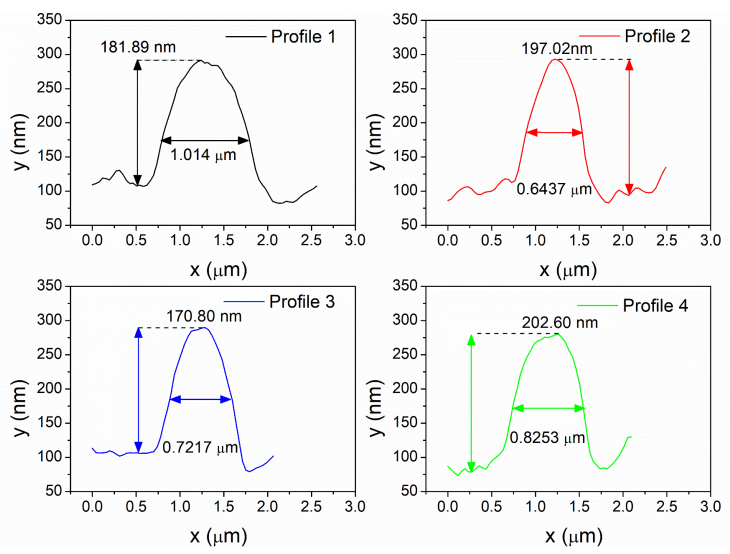

Figure 5. AFM topographic 2D and 3D images of LN2 nitrogen implanted die steel sample with the nominal fluence $1.0 \times 10^{18} \mathrm{at} / \mathrm{cm}^{2}$, with detailed profiles of four precipitates.

From these results, the best implantation conditions for the coinage dies were established: nominal fluence of $5.0 \times 10^{17} \mathrm{at} / \mathrm{cm}^{2}$ and room temperature. Using these conditions, two dies were implanted, obverse and reverse, and were tested on a press machine at the INCM facilities. During coin production, dies wear out and INCM operators follow the company's criteria to decide when to replace them: usually severe reliefs degradation and/or appearance of small cracks. The implanted dies had to be replaced after $\approx 100,000$ strokes, meaning a lifetime improvement identical to the standard dies with the Vautrol coating, i.e., the wear resistance was similar. However, the crack density was lower and the pattern was different from the usual one. With Vautrol coated dies, the most common sites of occurrence of cracks, highlighted in Figure 6 with white circles and dashes, are: the two ends of number 2 that lie near the edge of the die and between the globe and the edge (reverse), and near the stars that lie along the edge and also the lower limit of the cross for the national shield (obverse). As for the implanted dies, and marked in Figure 6 with white squares, the cracks appeared at the lower limit of the cross (obverse) and inside the globe and inside the 2 (reverse). This suggests the possibility of a surface shape impact on the role of the implantation process. A better understanding of these differences is being sought with new implantations to search for new routes to optimize the implantation process.

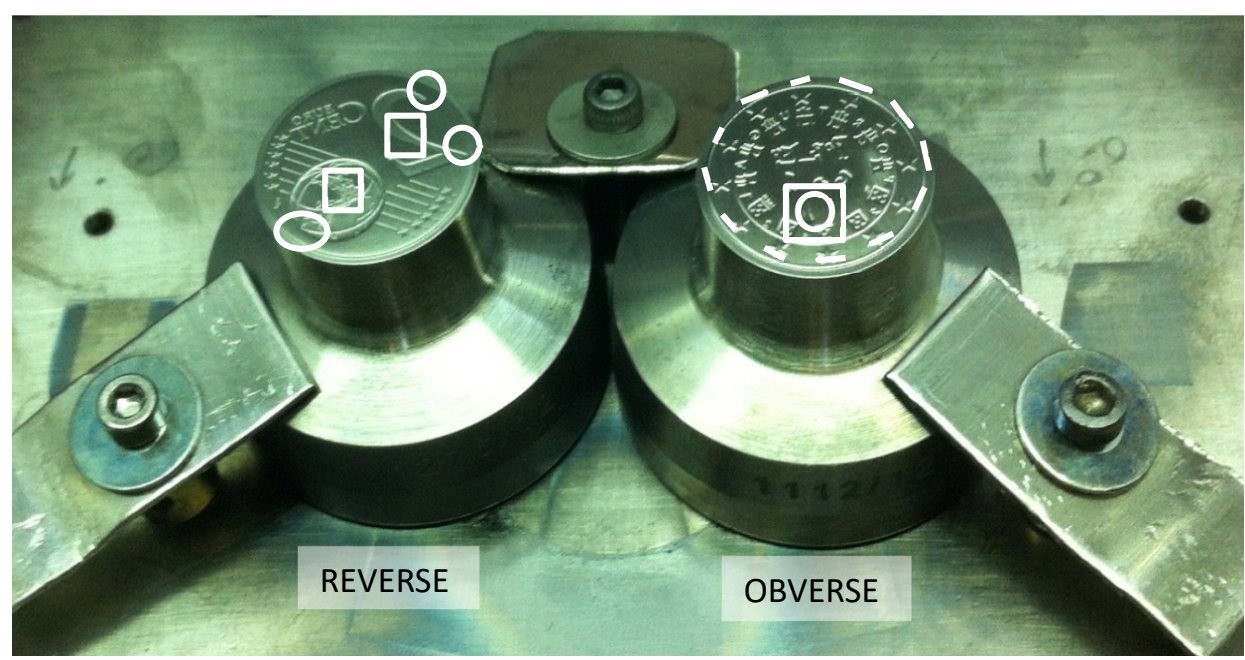

Figure 6. The most common sites of occurrence of fractures in the 2 euro cent coinage dies (marked in white circles) and the cracks that appeared in the implanted dies (marked in white squares). 


\section{Conclusions}

It was shown that high fluence $\left(5.0 \times 10^{17} \mathrm{at} / \mathrm{cm}^{2}\right)$ nitrogen ion implantation at room temperature resulted in a $\sim 40 \%$ (from $6.2 \pm 0.5$ to $8.7 \pm 0.7 \mathrm{GPa}$ ) hardness increase (values measured with $5 \mathrm{mN}$ loads). The implanted dies' lifetime was identical to the one obtained by standard methods already used by the Portuguese Mint house, so no meaningful wear resistance improvement was observed. However, the crack density was lower and the pattern was different.

Implantations at LN2 temperature and RT present similar hardness values, so no gain was obtained in cooling dies during nitrogen implantation. Implantation at this temperature is questionable for coinage dies due to a brittleness increase. Interestingly, a significant increase (factor two) in the depth reached by the implanted nitrogen was observed for LN2 implantations, which, to our knowledge, was never reported before. Under these conditions, the surface showed the formation of precipitates $(0.5-1 \mu \mathrm{m}$ in size) surrounded by small precipitates.

Author Contributions: Conceptualization, J.C. and E.A.; methodology, J.C.; software, J.C. and L.A.; validation, J.C., V.C., B.N., L.A., R.C. and E.A.; formal analysis, J.C., V.C., B.N. and L.A.; investigation, J.C.; resources, J.C., V.C., B.N., L.A., R.C. and E.A.; data curation, J.C. and B.N.; writing-original draft preparation, J.C. and B.N.; writing-review and editing, J.C., V.C., B.N., L.A., R.C. and E.A.; visualization, J.C. and B.N.; supervision, J.C.; project administration, J.C.; funding acquisition, J.C. All authors have read and agreed to the published version of the manuscript.

Funding: This research was funded by Fundação para a Ciência e a Tecnologia grants number UID/FIS/04559/2021 (LIBPhys) and UIDB/50022/2020 (IDMEC/LAETA).

Institutional Review Board Statement: Not applicable.

Informed Consent Statement: Not applicable.

Data Availability Statement: The data presented in this study are available upon request from the corresponding author.

Acknowledgments: The authors are indebted to Paulo Alexandrino and Paulo Leitão from INCM for providing the dies and for fruitful discussions.

Conflicts of Interest: The authors declare no conflict of interest.

\section{References}

1. BÖHLER. Available online: https:/ /www.bohler.at/export/en/ (accessed on 14 December 2021).

2. VTT. Available online: https:/ / www.vtt.de (accessed on 14 December 2021).

3. Iwaki, M. Tribological Properties of Ion-implanted Steels. Mater. Sci. Eng. 1987, 90, 263-271. [CrossRef]

4. Wang, T.M.; Li, B.Q.; Shi, J. The surface modification of 9Cr18 steel using nitrogen ion implantation. Surf. Coat. Technol. 1991, 50, 63-66. [CrossRef]

5. Dryzek, J.; Wiezorek, J.; Wollschlager, S.; Lekki, J.; Gottdang, A.; Cleff, B. Studies of point defects and tribological properties of nitrogen-implanted stainless steel. Mater. Lett. 1991, 12, 16-20. [CrossRef]

6. Bredell, L.J.; Malherbe, J.B. High dose implantation of nitrogen in tool steel: Auger electron spectroscopy and hardness measurements. Thin Solid Films 1993, 228, 267-271. [CrossRef]

7. Rodrigo, M.; Jiménez, C.; Váquez, L.; Alonso, F.; Fernández, M.; Martínez-Duart, J. Influence of nitrogen implantation on the properties of Ti and substoichiometric TiNx films deposited on high speed steel. J. Mater. Res. 1998, 13, 2117-2122. [CrossRef]

8. Li, M.; Knystautas, E.J.; Krishnadev, M. Enhanced microhardness of four modern steels following nitrogen ion implantation. Proc. SPIE 1998, 3413, 226-234. [CrossRef]

9. Bobji, M.S.; Biswas, S.K. Estimation of hardness by nanoindentation of rough surfaces. J. Mater. Res. 1998, 13, 3227-3233. [CrossRef]

10. Olofinjana, A.O.; Chen, Z.; Bell, J.M. Ultra-high surface hardness in nitrogen ion implanted low alloy steel. Mater. Lett. 2002, 53, 385-391. [CrossRef]

11. Kumar, N.; Kataria, S.; Dash, S.; Srivastava, S.K.; Das, C.R.; Chandramohan, P.; Tyagi, A.K.; Nair, K.G.M.; Raj, B. Tribological properties of nitrogen ion implanted steel. Wear 2012, 274-275, 60-67. [CrossRef]

12. Vlcak, P.; Fojt, J.; Weiss, Z.; Kopeček, J.; Perina, V. The effect of nitrogen saturation on the corrosion behaviour of Ti-35Nb-7Zr-5Ta beta titanium alloy nitrided by ion implantation. Surf. Coat. Technol. 2019, 358, 144-152. [CrossRef] 
13. Cisternas, M.; Bhuyan, H.; Retamal, M.J.; Casanova-Morales, N.; Favre, M.; Volkmann, U.G.; Saikia, P.; Diaz-Droguett, D.E.; Mändl, S.; Manova, D.; et al. Study of nitrogen implantation in Ti surface using plasma immersion ion implantation \& deposition technique as biocompatible substrate for artificial membranes. Mater. Sci. Eng. C 2020, 113, 111002. [CrossRef]

14. Piotrowska, K.; Madej, M.; Ozimina, D. Assessment of the Functional Properties of 316L Steel Alloy Subjected to Ion Implantation Used in Biotribological Systems. Materials 2021, 14, 5525. [CrossRef] [PubMed]

15. Xie X.; Chen, C.; Xu, J. Effect of Nitrogen Ion Implantation Energy on the Mechanical and Chemical Properties of AISI M50 Steel. Int. J. Chem. Eng. 2021, 2021, 4630661. [CrossRef]

16. Lindhard, J.; Scharff, M.; Schiott, H.E. Range Concepts and Heavy Ion Ranges. Mat. Fys. Medd. Dan. Vid. Selsk. 1963, 33, 14.

17. Ziegler, J.F.; Ziegler, M.D.; Biersack, J.P. SRIM-The stopping and range of ions in matter (2010). Nucl. Instrum. Methods Phys. Res. B 2010, 268, 1818-1823. [CrossRef]

18. Ryssel, H.; Ruge, J. Ion Implantation; John Wiley \& Sons: New York, NY, USA, 1986.

19. Alves, E.; Lorenz, K.; Catarino, N.; Peres, M.; Dias, M.; Mateus, R.; Alves, L.C.; Corregidor, V.; Barradas, N.P.; Fonseca, M.; et al. An insider view of the Portuguese ion beam laboratory. Eur. Phys. J. Plus 2021, 136, 684. [CrossRef]

20. Mayer, M.A. Improved Physics in SIMNRA 7. Nucl. Instrum. Methods Phys. Res. B 2014, 332, 176-180. [CrossRef]

21. Weller, M.R. A deficiency method. In Handbook of Modern Ion Beam Materials Analysis; Wang, Y., Nastasi, M., Eds.; Materials Research Society: Warrendale, PA, USA, 2009; pp. 65-67.

22. Cruz, J.; Silva, H.; Lopes, J.; Rocha, J.; Jesus, A.P. Very high fluence nitrogen implantations in metals studied by Rutherford Backscattering Spectrometry. Surf. Coat. Technol. 2018, 355, 169-173. [CrossRef] 